\title{
New QR Survey Methodologies to Analyze User Perception of Service Quality in Public Transport: The Experience of Madrid
}

\author{
Begoña Guirao, Ph.D. \\ Universidad Politécnica de Madrid \\ Antonio García \\ Consorcio Regional de Transportes de Madrid (CRTM) \\ María Eugenia López, Ph.D. \\ Universidad Politécnica de Madrid \\ Carlos Acha \\ ALSA Grupo \\ Julio Comendador, Ph.D. Candidate \\ Universidad Politécnica de Madrid
}

\begin{abstract}
Customer Satisfaction Surveys (CSS) have become an important tool for public transport planners, as improvements in the perceived quality of service lead to greater use of public transport and lower traffic pollution. Until now, Intelligent Transportation System (ITS) enhancements in public transport have traditionally included fleet management systems based on Automatic Vehicle Location (AVL) technologies, which can be used to optimize routing and scheduling, and to feed real-time information into passenger information channels. However, surveys of public transport users could also benefit from the new information technologies. As most customers carry their smartphones when traveling, Quick Response (QR) codes open up the possibility of conducting these surveys at a lower cost.

This paper contributes to the limited existing literature by developing the analysis of $Q R$ codes applied to CSS in public transport and highlighting their importance in reducing the cost of data collection and processing. The added value of this research is that it provides the first assessment of a real case study in Madrid (Spain) using QR codes for
\end{abstract}


this purpose. This pilot experience was part of a research project analyzing bus service quality in the same case study, so the QR code survey (155 valid questionnaires) was validated using a conventional face-to-face survey ( 520 valid questionnaires). The results show clearly that, after overcoming a few teething troubles, this QR code application will ultimately provide transport management with a useful tool to reduce survey costs.

Keywords: Public transport, Quality surveys, User perception, Information and Communication Technologies, ICTs, Quick Response codes, $Q R$ codes

\section{Customer Satisfaction Surveys in Public Transport}

The increase in Service Quality (SQ) in public transport has been shown to play a key role in attracting new passengers from private cars to the public transport system and in reducing traffic pollution as a result (Transportation Research Board 1999). The analysis of SQ perceived by passengers is of vital importance for both operators and public transport authorities. However, the concept of SQ is complex, fuzzy, and abstract, mainly because of the three aspects of service: intangibility, heterogeneity for each individual, and the inseparability of production and consumption (Parasuraman et al 1985). In addition to this complexity, a number of authors (Grönroos 1988) differentiate between consumer expectations and perception of service during the trip and maintain that the perception of SQ is the result of a comparison of consumer expectations with actual service performance. Other authors, such as $\mathrm{Hu}$ (2010), define service quality in terms of the difference between perceived quality and tolerable quality.

In any case, most research studies have analyzed only perceived service, and the only objective data for the operating companies is "quality of service provided," normally established in the concession contracts. One of the most interesting and practicallyminded SQ approaches comes from the European project QUATTRO (Quality Approach in Tendering Urban Public Transport), which presents a quality loop for the public transport system (European Union 1998), identifying four quality levels (see Figure 1), as follows:

- Expected quality - the level of quality desired by passengers and citizens in general.

- Perceived quality - the level of quality perceived - that is, observed more or less objectively-by passengers during their journeys.

- Targeted quality - the level of quality the company wishes to achieve. The targeted quality level is determined on the basis of expected quality, external and internal pressures, budgetary constraints, and competitors' performance.

- Delivered quality - the level of quality obtained, on a daily basis, in real operating conditions. 
FIGURE 1.

Quality loop at level of public transport system

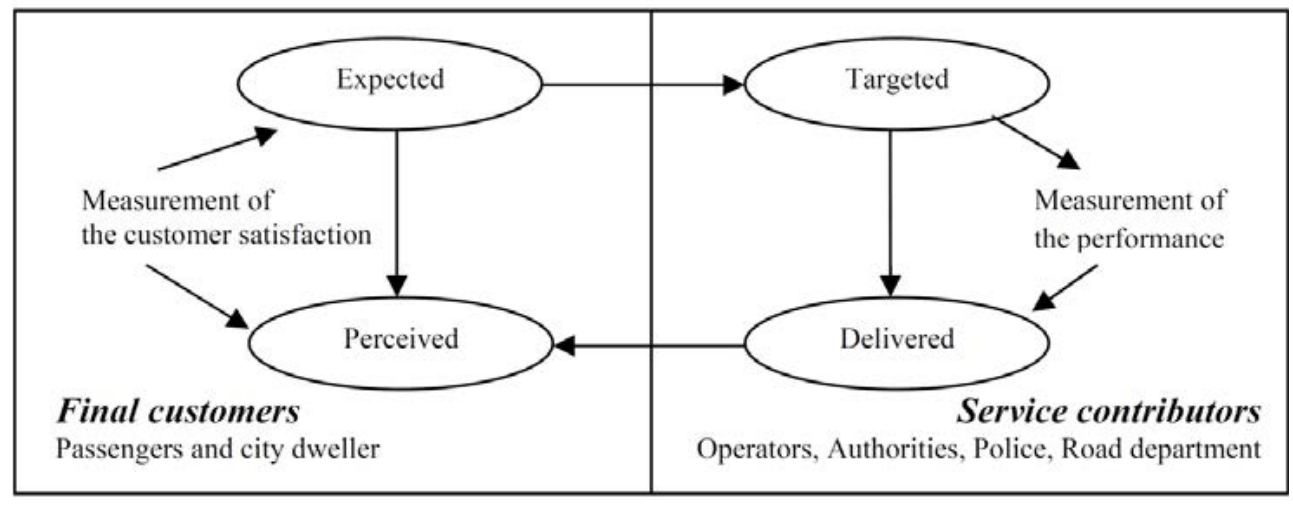

Source: QUATTRO, 1998

The main tools used to analyze service quality in public transport are based on Customer Satisfaction Surveys (CSS), usually carried out by operating companies. CSS results can help managers choose from a long list of service attributes (e.g., cleanliness, on-time performance, availability, comfort, security) to more optimally focus their organization's attention and resources. A considerable number of attributes are used to evaluate SQ, so they are normally grouped into a smaller number, called dimensions. Although there is no general agreement as to the nature or content of SQ dimensions, it is generally recognized that service quality is a multidimensional (Lehtinen and Lehtinen 1982), multilevel, or hierarchical (Brady and Cronin 2001) construct. Various papers (e.g., Eboli and Mazzulla 2007) have pointed to several categories of attributes that have a greater or lesser impact on SQ and satisfaction. In 2002, the European Committee for Standardization CEN (2003) established a quality standard-EN 13816, Service Quality Standard for Public Transport-in connection with QUATTRO research, and a final report. The EN 13186 standard classifies the characteristics of a service into basic, proportional, and attractive, depending on how compliance and non-compliance affects customer satisfaction. In the U.S., the Transit Capacity and Quality of Service Manual (TCQSM) (Transportation Research Board 2004) groups attributes into availability factors and comfort and convenience factors. The primary distinction made by the TCQSM is whether a transit service is offered; if it is, customers then consider both the type of availability (e.g., frequency or access) and comfort and convenience factors.

Once a group of attributes is selected for a specific survey, public transport operators and service industries need to know not only how the users rate the service on detailed service attributes (attribute-performance rating), but also the relative importance of these attributes to their customers (attribute-importance measures).

As indicated previously, CSS are widely used to analyze public transport quality, although the number of stated preference surveys has risen in recent years, mainly among academics. In conventional CSS, consideration of both of these factors (attribute-performance rating and attribute-importance measures) is crucial when the priority for the operator is to improve or sustain the current overall SQ. Normally, the rates are expressed on two scales: numeric or linguistic. Numeric scales are more widely used and have a wider range -3 to 11 points; linguistic scales are used less and have a narrower range -3 to 7 points (the 5-point Likert scales are the most widely adopted). 
The design of the survey format depends strongly on the approach used to estimate the relative importance of the attributes to the customers.

According to Weinstein (2000), there are basically two main approaches: stated importance and derived importance. Stated importance is based on asking customers to rate each attribute on an importance scale; this is the more intuitive and direct of the two methods, but requires a significant increase in the length of the questionnaire (which can lower the overall response rate and the accuracy of the survey). It also can sometimes fail to differentiate sufficiently between mean importance ratings; if customers score nearly all the measures near the top of the scale, certain attributes may be rated as important even though they, in fact, have little influence on overall satisfaction. In contrast, the derived importance approach is less intuitive and is based on "deriving" a measure of attribute importance by statistically testing the strength of the relationship of individual attributes with overall satisfaction. Academics have focused on this last approach, and stated-importance methods practically have been abandoned (when other survey formats—for example, ranking attributes_could have been studied).

Recent literature is now set on seeking other alternatives (to the common methods used until now) for deriving importance, namely (a) bivariate Pearson correlations, (b) factor analysis, and (c) multiple regression analysis. These other alternatives include Structural Equations Models (SEM), based on a multivariate technique combining regression, factor analysis, and analysis of variance to estimate interrelated dependence relationships simultaneously. This approach allows a phenomenon to be modeled by considering both the unobserved "latent" constructs and the observed indicators that describe the phenomenon. SEM has also been adopted to describe customer satisfaction in several public transport services such as metropolitan public transport (Lai and Chen 2011). More recently, De Oña et al. (2012) used decision trees to derive attribute importance in public transport quality. Decision trees is a novel nonparametric data-mining technique that does not predefine underlying relationships between dependent and independent variables.

The authors of this paper were working on new stated-importance methods when Quick Response (QR) code research came up. The case study was the Madrid-Tres Cantos corridor (Spain) with four bus lines, in which a new type of survey questionnaire (to state importance) was being tested using a more sophisticated process of analytic hierarchy to reduce the length of the survey questionnaire (not all users were asked for the same attribute ranking). A conventional survey was required to validate this new stated importance method (designed to derive importance) and, as the whole campaign was based on face-to-face surveys, the survey campaign was starting to become very costly. In this context, the research group began to develop further research lines with new methods to reduce the campaign cost using the new Intelligent Transport System (ITS). The valuable database offered a sound scenario for testing a new ITS tool-QR codes-and, in view of the fact that most customers carry their smartphones when they travel, QR codes opened up the opportunity to conduct these surveys at a lower cost. Therefore, a third type of questionnaire was designed for the $Q R$ survey (also derivedimportance) and uploaded to the operating company's (ALSA) website. The QR code would be a simple way to provide users with a virtual link to the questionnaire. 
This paper contributes to the limited existing literature by developing the analysis of QR codes applied to CSS surveys in public transport and highlighting their importance in reducing the cost of data collection and processing. The added value of this research lies in the first assessment of a real case study using $Q R$ codes. To describe the research as a whole, the paper is divided into the following parts: state of the art on SQ in the public transport sector and main objectives; description of the concept of QR codes and their current implementation in the public transport sector; case study description using a Spanish bus corridor located in Madrid (using a Spanish bus corridor located in Madrid) with a discussion of the results; validation of the $Q R$ survey using the conventional face-to-face CSS survey carried out in the same corridor; and presentation of the most important conclusions.

\section{Use of QR Codes in the Public Transport Sector}

Public transport can be made faster, more efficient, and more passenger-friendly by the use of ITS for traffic management and traveler support. Until now, ITS enhancements of public transport traditionally have included fleet management systems based on AVL technologies, which can be used to improve services, optimize routing and scheduling, and feed real-time information into various passenger information channels. However, surveys of public transport users, which are crucial for transport planners and operators (as discussed above), could also benefit from the new information technologies. In recent years and with increasing intensity, QR codes seemingly have invaded almost all the advertising spaces in our media.

A "QR code" is the trademark for a type of matrix barcode (or two-dimensional barcode) first designed for the automotive industry in Japan. QR codes were developed in 1994 by a Toyota subsidiary, Denso Wave, to help track automobile parts throughout production. This technology has been around for more than a decade and recently became popular as a medium for marketers to reach smartphone users. QR codes are have been used in marketing, inventory control, and manufacturing in Japan and Europe for the last 10 years (Sankara Narayanan 2012). A QR code consists of black modules (square dots) arranged in a square grid on a white background, which can be read by an imaging device (such as a camera) and processed using Reed-Solomon error correction until the image can be appropriately interpreted. The required data are then extracted from patterns present in both the horizontal and vertical components of the image. While designing a $Q R$ code may appear complex, creating ready-to-use $Q R$ codes is easy using free online $Q R$ code generators (Coleman 2011). Some of the advantages of $Q R$ codes for customers over traditional URLs are that they are potentially faster and easier to access the website, and they are not susceptible to typing errors.

As most customers carry their smartphones when they travel, QR codes open up the possibility of conducting customer satisfaction surveys at a lower cost, although this is not the primary application of this tool in the public transport sector. There are currently two main QR code implementations: e-ticketing (European Parliament 2014; Zhang et al. 2012; Finzgar and Trebar 2011) and real-time user information (Eken and Sayar 2014; Ganesan et al. 2012). Passenger transport companies all around the world use $Q R$ codes instead of paper tickets, almost all airlines offer boarding passes on mobile 
phones, and long-distance and high-speed trains and some interurban bus companies use $\mathrm{QR}$ codes for ticketing.

Customer information is another application of QR codes in the transport sector. Many public transport companies already use GPS to track their vehicles, which enables location-based services through a web page connection. For example, QR codes can be printed at bus stop shelters, providing smartphone travelers with direct access to realtime bus departure information for the stop (Figure 2).

FIGURE 2.

Scanning a QR code with a smartphone
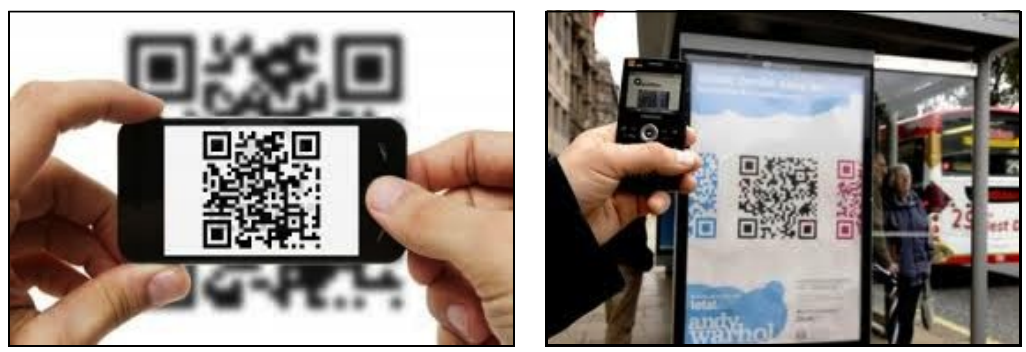

It should be noted that these two main QR code implementations in the public sector (e-ticketing and user information) require very different customer attitudes towards the new ITS device. When QR codes are used for e-ticketing, the company provides both the code and the scanner to read the code, and the customer attitude can be "passive." However, when QR codes are used for customer information and even surveys, the company provides the code but the customer must have a means of scanning the code and knowing how to use it. In the latter case, an "active" customer attitude is needed to achieve a successful result.

There are many case studies in the world in which QR codes have been applied to e-ticketing or user information in the public transport sector. However, to date, there has been little research exploring the use of QR codes as a procedure for collecting customer surveys. This approach is based on printed $Q R$ codes being provided to the users on board. Because QR codes can store addresses and Uniform Resource Locators (URLs), travelers with a camera phone equipped with the correct reader application can scan the QR code and open the operator's web page in the telephone's browser. The questionnaire can be located on the web page and the answers stored automatically. This could mean a significant reduction in the cost of the survey campaign and a faster information processing method.

The authors found very few similar experiences in the literature, although web-based surveys have been studied in depth in other sectors (Greenlaw and Brown-Welty 2009; Lin and Van Ryzin 2012), and there is interesting research in the U.S. on web-based transit surveys. For example, Cummins et al. (2013) compared responses to paper customer satisfaction surveys distributed on board and surveys e-mailed to a list of agency passengers. More recently, Agrawal et al. (2015) investigated the relative data quality of three different bus passenger survey methods distributed or administered on the transit vehicle: self-completed paper surveys, self-completed online surveys (with URLs or QR codes provided), and interviewer-assisted tablet-based surveys. Apart from 
this U.S. experience, the European experience described in this paper helps to fill the gap in terms of $\mathrm{QR}$ codes, and the only way to validate our $\mathrm{QR}$ code survey was using the results of a conventional face-to-face CSS in the same bus corridor.

One of the main requirements for obtaining a representative sample in a survey using $\mathrm{QR}$ codes is that the users must be familiar with the technology and own a smartphone. The adoption of a new technology often is affected by its perceived utility and ease of use, both of which could vary due to cognitive differences according to age. Recent literature has analyzed age differences in the knowledge and usage of QR codes (Mendelson and Romano 2013). Overall, self-reported awareness, knowledge, and usage tend to be lower among older adults than younger and middle-age adults Moreover, given that smartphones are necessary to use QR codes, the need to own one imposes a ceiling on the number of people who are able to use QR codes on a regular basis. The willingness to share personal data and the existence (and timing) of a reward for completing the survey, as with any type of survey (not only online ones) will be two key user factors for the success of the survey campaign. Much can be inferred from the influence of these two factors when using QR codes in loyalty campaigns (Okazaki et al. 2013). Recently, an increasing number of firms have shown interest in including $Q R$ codes in their promotional campaigns, and a quality survey of public transport users could learn from this approach. Our experience in Madrid confirms the Okazaki et al. (2013) findings on QR code promotion; we can expect a significant interaction effect between the existence and timing of rewards and the level of user involvement. As described in the next section, the offer of a reward was one of the tools used by the research group to obtain a representative sample in the case study.

\section{Case Study: Customer Satisfaction Survey in a Bus Corridor in Madrid}

The initiative to conduct a quality survey among urban bus users using $Q R$ codes is part of an ongoing research project led by the Universidad Politécnica de Madrid (UPM). The methodology included a conventional face-to-face survey campaign carried out in March 2013 in four peri-urban bus lines along the Madrid-Tres Cantos corridor and operated by the company ALSA. Figure 3 shows the location of the corridor. Bus lines 712, 713, and 716 connect the Madrid Public Transport Interchange Hub-Plaza de Castilla to the city of Tres Cantos along the M-607 corridor (a dual carriageway with two lanes in each direction). The last part of the route, already in Tres Cantos, separates into different routes inside the city. Line 714 is a special case, since it connects the interchange hub to the campus of Universidad Autónoma de Madrid (UAM), a few kilometres outside the city, which makes this bus service a specialized line for trips for the purpose of study.

To achieve the objectives of the research project, two previous groups of questionnaires were designed-one to determine the derived attribute importance (Group 1) and the other to find the stated importance (Group 2). Only Group 1 was used to validate the $\mathrm{QR}$ survey, as the format was comparable. Following some parameters of statistical significance and maximum error, 800 surveys were estimated, and 787 were conducted (520 from Group 1 and 276 from Group 2), from which 731 observations were drawn as valid. These results allowed the quality analysis to be completed with a sufficient sample 
size for the planned objectives. The pilot survey was carried out on February 20, 2013, and definitive surveys were made throughout the last week of March from 6:00-11:00 AM (18.3\% of the sample), 11:01 AM-4:40 PM (64.8\%), and 4:41-11:00 PM (16.9\%), at both the main bus stops (Plaza de Castilla Interchange Hub, La Paz Hospital, Ramón y Cajal Hospital, Einstein-Rectorado UAM) and on board.

FIGURE 3.

Location of Madrid-Tres Cantos corridor (M-607 dual carriageway) in Spain

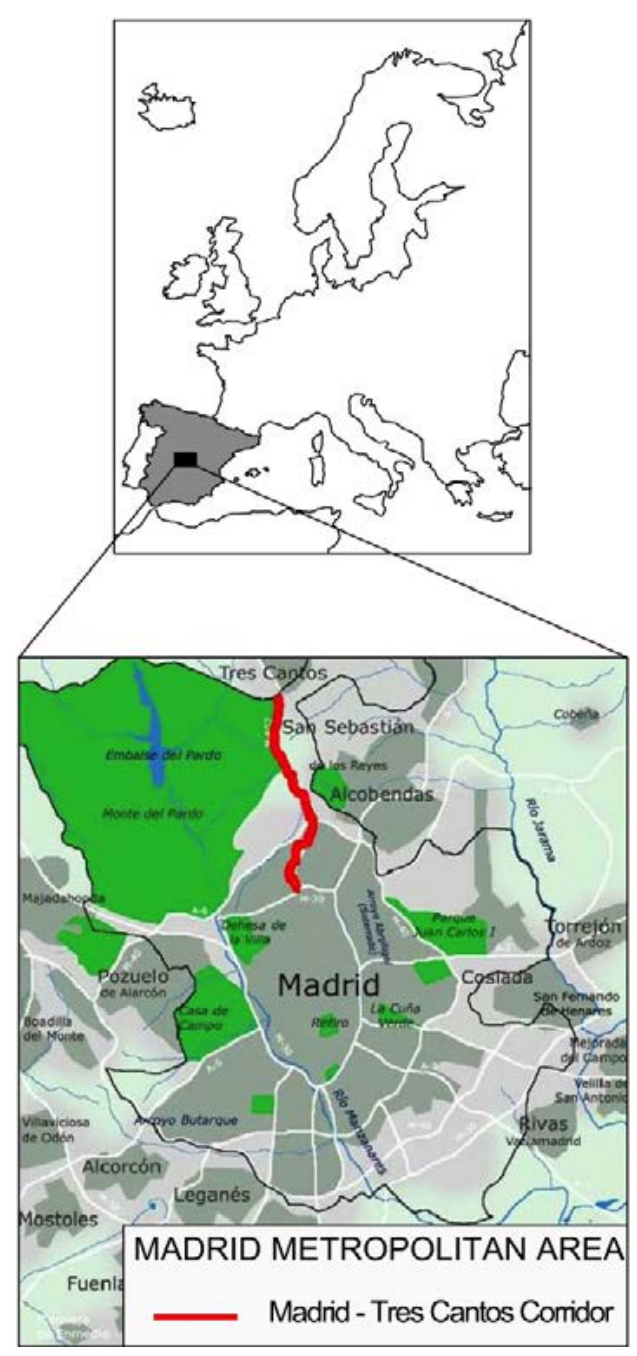

Table 1 shows the sample rate for each line for survey Group 1 (designated "conventional survey"). These sample rates present errors of around 5-7\% for high confidence intervals. Line 714 has a distinct student dimension and, although the sample rate is low, the results are still considered sufficient for the analysis. All the bus lines have a similar age and gender distribution except for line 714-due to the fact that it is used mainly by students, it has a higher percentage of young users, and it also has more women than men. In the conventional survey, the number of valid questionnaires per user and trip profile (ticket type, gender, activity, frequency, age, and trip purpose) also are shown with their percentages in Table 1. 
TABLE 1.

Conventional Survey Collection per Bus Line -

Sample Rates and Questionnaires Collected per User and Trip Profile

\begin{tabular}{|c|c|c|c|c|c|}
\hline & Line 712 & Line 713 & Line 714 & Line 716 & Total \\
\hline \multicolumn{6}{|c|}{ Sample Rate Estimation } \\
\hline Working day demand (trips) & 4,106 & 3,072 & 3,250 & 3,160 & 13,588 \\
\hline No. of surveys collected & 207 & 116 & 91 & 106 & 520 \\
\hline Sample rate & $5 \%$ & $3.8 \%$ & $2.8 \%$ & $3.4 \%$ & $3.8 \%$ \\
\hline \multicolumn{6}{|c|}{ Number of Valid Questionnaires per User and Trip Profile } \\
\hline \multicolumn{6}{|l|}{ User Activity } \\
\hline Working & $112(54.1 \%)$ & $68(58.6 \%)$ & $17(18.7 \%)$ & $62(58.5 \%)$ & $259(49.8 \%)$ \\
\hline Unemployed & $11(5.3 \%)$ & $6(5.2 \%)$ & $1(1.1 \%)$ & $2(1.9 \%)$ & $20(3.8 \%)$ \\
\hline Retired & $26(12.6 \%)$ & $9(7.8 \%)$ & $6(6.6 \%)$ & $6(5.7 \%)$ & $47(9.0 \%)$ \\
\hline Student & $43(20.8 \%)$ & $26(22.4 \%)$ & $67(73.6 \%)$ & $29(27.4 \%)$ & $165(31.7 \%)$ \\
\hline Other & $15(7.3 \%)$ & $7(6.0 \%)$ & $0(0.0 \%)$ & $7(6.6 \%)$ & $29(5.6 \%)$ \\
\hline \multicolumn{6}{|l|}{ Ticket } \\
\hline Single & $10(4.8 \%)$ & $6(5.2 \%)$ & $0(0.0 \%)$ & $7(6.6 \%)$ & $23(4.4 \%)$ \\
\hline 10 trips & $16(7.7 \%)$ & $10(8.6 \%)$ & $2(2.2 \%)$ & $5(4.7 \%)$ & $33(6.3 \%)$ \\
\hline Season ticket & $176(85.0 \%)$ & $99(85.3 \%)$ & $89(97.8 \%)$ & $94(88.7 \%)$ & $458(88.1 \%)$ \\
\hline Other & $5(2.4 \%)$ & $1(0.9 \%)$ & $0(0.0 \%)$ & $0(0.0 \%)$ & $6(1.2 \%)$ \\
\hline \multicolumn{6}{|l|}{ Frequency of trip } \\
\hline$\geq 5$ days & $142(68.6 \%)$ & $84(72.4 \%)$ & $65(71.4 \%)$ & $73(68.9 \%)$ & $364(70.0 \%)$ \\
\hline 3-4 days & $22(10.6 \%)$ & $14(12.1 \%)$ & $13(14.3 \%)$ & $11(10.4 \%)$ & $60(11.5 \%)$ \\
\hline $1-2$ days & $31(15.0 \%)$ & $9(7.8 \%)$ & $10(11.0 \%)$ & $13(12.3 \%)$ & $63(12.1 \%)$ \\
\hline Less than 1 day & $12(5.8 \%)$ & $9(7.8 \%)$ & $3(3.3 \%)$ & $9(8.5 \%)$ & $33(6.3 \%)$ \\
\hline \multicolumn{6}{|l|}{ Trip purpose } \\
\hline Work & $117(56.5 \%)$ & $65(56.0 \%)$ & $15(16.5 \%)$ & $63(59.4 \%)$ & $260(50.0 \%)$ \\
\hline Study & $38(18.4 \%)$ & $23(19.8 \%)$ & $71(78.0 \%)$ & $25(23.6 \%)$ & 157 (30.2\%) \\
\hline Medical & $11(5.3 \%)$ & $8(6.9 \%)$ & $0(0.0 \%)$ & $4(3.8 \%)$ & $23(4.4 \%)$ \\
\hline Leisure & $10(4.8 \%)$ & $3(2.6 \%)$ & $0(0.0 \%)$ & $3(2.8 \%)$ & $16(3.1 \%)$ \\
\hline Other & $31(15.0 \%)$ & $17(14.7 \%)$ & $5(5.5 \%)$ & $11(10.4 \%)$ & 64 (12.3\%) \\
\hline \multicolumn{6}{|l|}{ Age } \\
\hline$\leq$ to 23 & $48(23.2 \%)$ & $22(19.0 \%)$ & $60(65.9 \%)$ & $30(28.3 \%)$ & $160(30.7 \%)$ \\
\hline $23-35$ & $59(28.5 \%)$ & $33(28.4 \%)$ & 19 (20.9\%) & $24(22.6 \%)$ & 135 (25.9\%) \\
\hline $36-50$ & $38(18.4 \%)$ & $30(25.9 \%)$ & $7(7.7 \%)$ & $29(27.4 \%)$ & $104(20.0 \%)$ \\
\hline$\geq 50$ & $62(30.0 \%)$ & $31(26.7 \%)$ & $5(5.5 \%)$ & $23(21.7 \%)$ & $121(23.2 \%)$ \\
\hline \multicolumn{6}{|l|}{ Gender } \\
\hline Male & $66(31.9 \%)$ & 37 (31.9\%) & $33(36.3 \%)$ & $41(38.7 \%)$ & 177 (34.0\%) \\
\hline Female & $141(68.1 \%)$ & 79 (68.1\%) & $58(63.7 \%)$ & $65(61.3 \%)$ & $343(66.0 \%)$ \\
\hline TOTAL & 207 (39.8\%) & $116(22.3 \%)$ & 91 (17.5\%) & $106(20.4 \%)$ & $520(100 \%)$ \\
\hline
\end{tabular}


In the conventional survey, in addition to the overall level of satisfaction with the service, the users were asked to rate the following attributes:

- Route (route of the line)

- Connections (connection with other lines and transport modes)

- Punctuality (on-time performance)

- Frequency (timetable and headway)

- Access (ease of access to the bus stop from origin -home, work, university, etc.)

- Information-incidents (delays, breakdowns, changes in the line, etc.)

- Cleanliness (cleanliness of the bus)

- Information-service (timetables, routes, etc.)

- Journey time (of the route)

- Comfort (air conditioning, seating, etc.)

- Information and Communication Technologies (ICTs) (Internet on board, mobile payment, real-time information screens both on-board and at stops)

- Shelters (along the route)

The statistical mode and median of the results of the analysis of the bus lines show that most of the variables had an average and median of "good"; only the variable "frequency" was deemed "not good" for the median, which indicates the importance of this variable and how it is valued by respondents. The statistical analysis by line does not reveal any substantial difference, except for the case of the valuation of ICTs by the users of line 714, who describe it as "very good." This valuable database offered a sound scenario for testing a new ITS tool, and the research group assumed that in line 714, 60\% of whose users are young students, the response rate using $Q R$ codes should be fairly acceptable. Nevertheless, the pilot survey of February 20 clearly showed that this first experience would run into quite a few difficulties. That same day, after posting the $Q R$ codes on the shelters of line 714 and designing a very simplified survey format (to make it short and schematic), only 10 surveys were registered on the bus operator website. The following reasons were found for this lack of success:

1. The use of $Q R$ codes requires not only the availability of a device with Internet access (phone, $P C$, tablet), but also a minimum knowledge of how to read a $Q R$ code (as discussed earlier). This means that people who have never used a $Q R$ code will not do so on the day of the survey if they are not sufficiently motivated and if they are not equipped with an application (app) for capturing and reading QR codes.

2. The saturation of $Q R$ codes for advertising purposes means that users have no particular interest in accessing a website with this kind of format. A reward could help achieve a higher level of user involvement in the survey (as demonstrated in QR loyalty campaigns for companies). 
3. Posting the QR code on the bus shelters means that many users arriving just in time to board the bus fail to realize that they have the opportunity to fill in the questionnaire. and posting the $\mathrm{QR}$ code inside the bus may be insufficient to achieve a high response rate.

After this experience, it was decided to hand out the $Q R$ code printed on a piece of paper (a colorful book separator sheet provided by the operator, ALSA) at the access door of each bus that clearly explained how to read the $Q R$ code (see Figure 4). Following the experience of $Q R$ loyalty campaigns carried out by companies, participants also were eligible to win a tablet as a reward. Thus, in only one day, 155 valid surveys were registered on the operator's website, and this sample was validated using the conventional survey results for line 714 .

\section{FIGURE 4. \\ QR code handout}

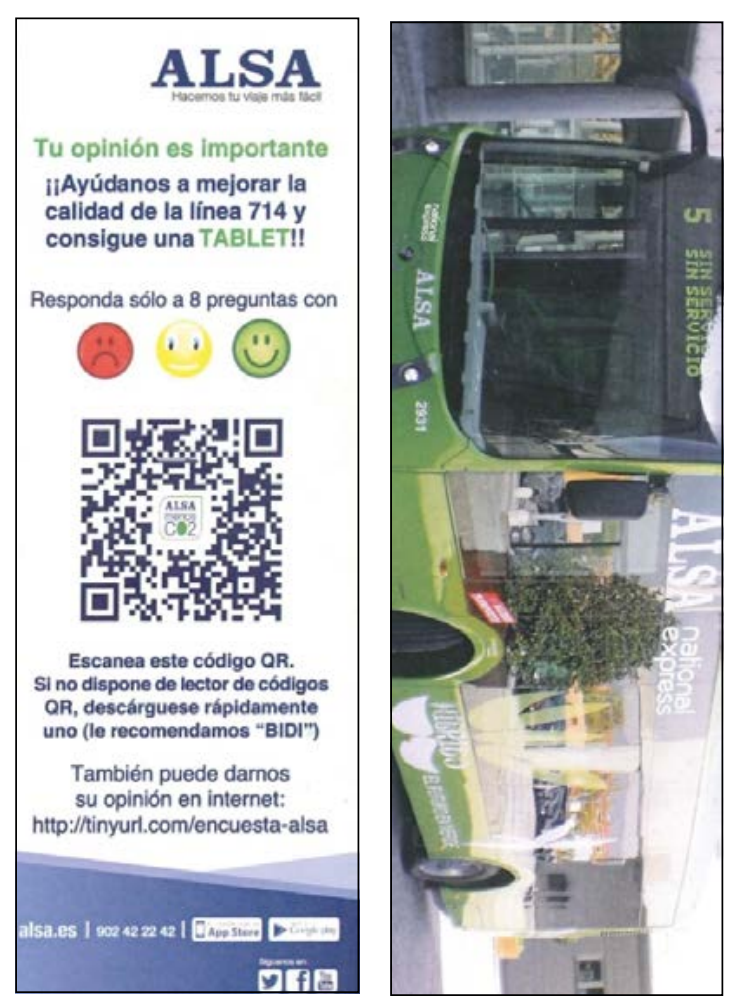

The survey format was simplified for two main reasons: the movement of the bus could prevent most users from reading a long and detailed survey on their smartphones (particularly standing passengers), and there was a space limitation due to the size of the smartphone screen. This made it necessary to select only a few SQ attributes (only the most relevant were chosen) and to reduce the length of the questions. The scale of response was also changed from five to three options (Good, Quite Good, and Not Good At All), and these were represented with emoticons (see Figure 4) to give the survey a more informal and user-friendly appearance. 


\section{Validation of QR Survey}

The statistical tool used to compare the results of the two surveys was the Student's $t$-test for independent samples, which guarantees that the perception of quality attributes (how users rate each SQ attribute) is the same regardless of the type of survey used. The Student's t-test is any test in which the statistic has a Student's t distribution if the null hypothesis is accepted. It is used when the population studied follows a normal distribution but the size of the sample is so small that the statistics on which the inference is based are not normally distributed. An estimate of the standard deviation is used rather than the real value.

The t-test for independent samples was used to compare means between two different samples. It could then be determined whether the attribute perception captured by the $\mathrm{QR}$ survey differs from the conventional survey. Assuming that the variances of the variables are different, this test analyzed whether the probability associated to $t$ is higher than 0.05 . This means that the null hypothesis is accepted-there is no difference in the measurement of each quality attribute with the $Q R$ and the conventional survey. SPSS software was used for the statistical analysis of this case study.

Once the statistical tool was defined, it was no easy task to validate the QR code survey. It should be noted for the comparative statistical analysis that the format of the perception survey was different, since to simplify the survey, the semantic (linguistic) scale of response was changed from five to three options, and respondents were asked to rate their perception of a smaller number of attributes. As an example, in the semantic (linguistic) scale used in the QR survey (Good, Quite good, Not Good At All), many intermediate levels of perception were overlooked. It was, therefore, necessary to reach a consensus on the design of the $Q R$ survey format to ensure that its simplicity allowed nuances to be captured. In any case, it was necessary to standardize the questions in the two surveys (see Table 2) before conducting the Student's t-test for independent samples. In most cases, the need to reduce the length of a survey entails a real risk of losing part of the required information.

TABLE 2. Comparative Analysis of Conventional and QR Surveys

\begin{tabular}{|l|l|l|}
\hline \multicolumn{1}{|c|}{$\begin{array}{c}\text { Conventional Survey } \\
\text { How do you rate the following features? }\end{array}$} & Following is a brief questionnaire on service quality. & \multicolumn{1}{c|}{$\begin{array}{c}\text { Service Quality } \\
\text { Attribute }\end{array}$} \\
\hline Bus schedule and frequency of buses & How do you rate the bus frequency? & Frequency \\
\hline Bus punctuality & How do you rate the bus punctuality? & Punctuality \\
\hline Comfort on board: seats, air conditioning etc. & Is it easy to find a seat during the trip? & Seats \\
\hline User information (timetables, fares, etc.) & How do you rate the information to the user? & User information \\
\hline Duration of the bus route & How do you rate the trip time? & Trip time \\
\hline Trip itinerary & How do you rate the service in this route? & Route \\
\hline
\end{tabular}


The authors acknowledge that the simplification of the QR survey severely conditioned the validation and significance of the study results, and this fact should be corrected in further survey campaigns. Table 3 shows not only the comparative results of the statistical indexes (average, standard deviation and standard error) but also the results of the t-test for independent samples. The results seem to show that in spite of the different format and structure of both surveys, the measurement of the perception indicators-except for the attributes "seats" and "trip time"- does not appear to depend on the kind of survey. Indeed, as in Table 3, the wording of the questions for measuring both variables was not homogeneous, meaning that the users may have thought they were being asked about different attributes. The remaining attributes that were rated using similar wording were considered to have been validated, although there were some issues that require discussion. As noted by some leading experts in the field of transit passenger surveys (referring to this case study), from a strictly experimental viewpoint, comparative analysis is much better served when all key variables except for the item being tested (in this case, the survey method) are held constant. The fact that the satisfaction questions varied between the two survey methods raises some question about the results. The selection of a line with a ridership composed primarily of university students avoids the issue of how many riders have smartphones, and a QR-based survey would over-sample certain portions of current ridership and under-sample others. Validation is also threatened by different wording for terms such as "seats" and "trip time" and for other SQ attributes such as "frequency," "route," and "user information." "User information" included specific examples of information in the paper survey but not in the online survey, and the difference in results was borderline significant. Indeed, "bus schedule" and "frequency" are not exactly the same concept, and the "route" questions appear to be worded differently.

TABLE 3. Results of Student's t-Test for Independent Samples with Prior Comparison of Statistical Indexes

\begin{tabular}{|c|c|c|c|c|c|c|c|c|c|}
\hline & & \multicolumn{4}{|c|}{ Comparison of Statistical Indexes } & \multicolumn{4}{|c|}{$\begin{array}{l}\text { Student's t-test for Independent } \\
\text { Samples }\end{array}$} \\
\hline Attribute & Type of Survey & $N$ & Average & $\begin{array}{l}\text { Standard } \\
\text { Deviation }\end{array}$ & $\begin{array}{c}\text { Standard } \\
\text { Error }\end{array}$ & $t$ & $\begin{array}{c}\text { Sig. } \\
\text { (bilateral) }\end{array}$ & $\begin{array}{c}\text { Average } \\
\text { differences }\end{array}$ & $\begin{array}{c}\text { Standard } \\
\text { error } \\
\text { differences }\end{array}$ \\
\hline \multirow{2}{*}{ Frequency } & Conventional & 91 & 3.6044 & 0.84168 & 0.08823 & \multirow{2}{*}{-1.0} & \multirow{2}{*}{0.30} & \multirow{2}{*}{-0.14} & \multirow{2}{*}{0.14} \\
\hline & QR & 155 & 3.7484 & 1.29230 & 0.10380 & & & & \\
\hline \multirow{2}{*}{ Punctuality } & Conventional & 91 & 4.0220 & 0.75980 & 0.07965 & \multirow{2}{*}{-0.2} & \multirow{2}{*}{0.85} & \multirow{2}{*}{-0.02} & \multirow{2}{*}{0.13} \\
\hline & QR & 155 & 4.0452 & 1.21325 & 0.09745 & & & & \\
\hline \multirow{2}{*}{ Seats } & Conventional & 91 & 3.9341 & 0.67991 & 0.07127 & \multirow{2}{*}{3.8} & \multirow{2}{*}{0.00} & \multirow{2}{*}{0.50} & \multirow{2}{*}{0.13} \\
\hline & QR & 155 & 3,4387 & 1.39146 & 0.11176 & & & & \\
\hline \multirow{2}{*}{ Information } & Conventional & 91 & 4.0220 & 0.77428 & 0.08117 & \multirow{2}{*}{2.1} & \multirow{2}{*}{0.05} & \multirow{2}{*}{0.29} & \multirow{2}{*}{0.14} \\
\hline & QR & 155 & 3.7355 & 1.45975 & 0.11725 & & & & \\
\hline \multirow{2}{*}{ Trip time } & Conventional & 91 & 4.0989 & 0.63342 & 0.06640 & \multirow{2}{*}{-2.7} & \multirow{2}{*}{0.01} & \multirow{2}{*}{-0.27} & \multirow{2}{*}{0.10} \\
\hline & $\mathrm{QR}$ & 155 & 4.3677 & 0.98705 & 0.07928 & & & & \\
\hline \multirow{2}{*}{ Route } & Conventional & 91 & 4.1209 & 0.66391 & 0.06960 & \multirow{2}{*}{0.5} & \multirow{2}{*}{0.66} & \multirow{2}{*}{0.05} & \multirow{2}{*}{0.11} \\
\hline & $Q R$ & 155 & 4.0710 & 1.12302 & 0.09020 & & & & \\
\hline
\end{tabular}


Despite all these drawbacks, this pilot experience reveals most of the potential challenges facing transit agencies when deploying online surveys. Using QR surveys to measure quality of service is an acceptable practice as long as a representative sample is achieved, and every effort should be made to obtain a high level of respondent involvement. It should be noted that previous research works in the U.S. (Spitz et al. 2006) found a strong perception among U.S. transit agencies that respondents of on-line surveys (not specifically QR) were not representative of transit passengers generally. However, almost 10 years after the publication of these studies, smartphones and the cost of data plans are becoming cheaper (they probably are cheaper now in Europe than in the U.S.), making smartphones affordable to a larger number of people, which possibly would contribute to obtaining a high number of valid questionnaires.

One of the main targets of using this QR code application was ultimately to provide transport management with a useful tool for reducing transit agency survey costs. We estimated the cost reduction when using $Q R$ codes compared to conventional survey costs, considering the period of the survey campaign and the labor costs (per completed survey) in both experiences. Labor costs included survey development, deployment (survey campaign), and tabulation of the results. Our QR experience show reductions of more than $40 \%$ compared to conventional survey costs. This figure may be reduced in future experiences after correcting the problems detected in the pilot survey, and even in the definitive survey (which implies increased labor costs).

Finally, another important issue in this kind of campaign is the time period of the survey-namely, whether it should be conducted during the trip. From the authors' experience in the Madrid-Tres Cantos corridor, the website associated to the QR code was active the whole of the day of the survey until midnight. This implies that the survey could be filled in by non-passengers who had access to the QR code simply to obtain the reward, although from the similar performance of the samples (perception survey for line 714 and QR survey), this does not seem to be the case. However, this kind of risk could be partly avoided in future $Q R$ surveys by limiting the web access strictly to the period of the survey or, at most, to a few more hours. Other improvements could be implemented in the future to limit non-passenger access to the survey, including printing a single $Q R$ code per card to ensure that each code is used only once. This would require each card to have a different $Q R$ code associated to a unique numbered survey. After filling out the survey, each $Q R$ code would expire.

\section{Conclusions and Recommendations}

Traditional and recent literature on service quality provides policymakers with a large number of tools to obtain a global satisfaction index and quantify the importance of the attributes to passenger perceived quality. However, there has, so far, been little research exploring the best format and method of conducting the surveys to ensure a consistent database and reduce survey campaign costs. ITS enhancements to public transport traditionally have included fleet management systems based on AVL technologies, which can be used to improve services, optimize routing and scheduling, and feed realtime information into passenger information channels. Currently, there are two major QR code implementations in the public transport sector: e-ticketing and real-time user 
information; however, surveys of public transport users, who are so crucial for transport planners and operators, have scarcely benefited from this new information technology.

The first experience using QR codes for a SQ survey in Spain was carried out in the Madrid-Tres Cantos corridor on one of the four bus lines operated by ALSA. The lessons learned from the failures of the pilot survey campaign were considerably more useful than those obtained through the validation process (using a Student t-test for independent samples). The $Q R$ survey was validated using a conventional face-to-face survey database, although the differences between the two questionnaire formats required a previous analysis of homogeneity and generated an important discussion on its significance. Differences in wording should be avoided in any repetition of these $Q R$ surveys to strengthen the validation process. The pilot survey confirmed some of the statements in the recent literature regarding the use of QR codes in loyalty campaignsfamiliarity with QR codes and usage together with self-reported awareness is a key issue in this kind of survey. In this case study, despite the fact that the users of bus line 714 were university students traveling with a smartphone, many of them had never used a $\mathrm{QR}$ code before. The $\mathrm{QR}$ code also must be clearly visible, and simply posting the $\mathrm{QR}$ code on a bus shelter proved insufficient; one solution may be to hand out the printed $\mathrm{QR}$ code. Finally, as in the majority of surveys, respondent involvement may increase if some reward is clearly announced and delivered in the campaign.

After this experience, recommendations focus on the design of a prior pilot survey to quantify, in each case study, user smartphone availability and their QR knowledge and usage. Users smartphone availability is the only variable that can clearly condition the survey campaign, and any remaining problems detected during the pilot survey can be overcome, as shown in this research. This paper contributes to the limited existing literature by developing the analysis of QR codes applied to CSS surveys in public transport and highlighting their impact in reducing the cost of data collection and processing. The results clearly show most of the challenges facing transit agencies when deploying this type of online survey. If these challenges can be overcome, the application of QR codes will provide future transport policymakers with a useful tool for reducing survey costs.

\section{Acknowledgments}

The conclusions reached in this article are derived from an ongoing research work on service quality in public transport carried out by the authors of this paper as members of the Department of Transport at the Universidad Politécnica de Madrid (UPM) and the Consorcio Regional de Transportes de Madrid (CTRM). ALSA Group (the bus operator) made significant contributions to this research, particularly with regard to designing the customer satisfaction survey, authorizing on-board survey campaigns, and making bus staff available to the research team during the days of the study. The authors would like to thank the anonymous paper reviewers for their valuable comments and suggestions to improve the quality of the paper. 


\section{References}

Agrawal, A. W., S. Granger-Bevan, G. L. Newmark, and H. Nixon. 2015. "Comparing Data Quality and Cost from Three Modes of On-Board Transit Surveys." Proceedings of 2015 TRB Annual Meeting, Transportation Research Board.

Brady, M. K., and J. J. Cronin. 2001. "Some New Thoughts on Conceptualizing Perceived Service Quality: A Hierarchical Approach." Journal of Marketing, 65(3): 34-49.

Cummins, B., G. Spitz, T. P O'Malley, and M. Campbell. 2013. "How Close is Close Enough? Statistical Equivalence of Onboard versus Online Surveys of Transit Customers." Presented at the 92nd Annual Meeting of the Transportation Research Board, Washington, DC.

De Oña J., R. de Oña, and F. J. Calvo. 2012. "A Classification Tree Approach to Identify Key Factors of Transit Service Quality." Expert Systems with Applications, 39: 11164-11171.13.

Eboli, L., and G. Mazzulla. 2007. "Service Quality Attributes Affecting Customer Satisfaction for Bus Transit." Journal of Public Transportation, 10(3): 21-34.

Eken, S., and Sayar, A. 2014. "A Smart Bus Tracking System Based on Location-Aware Services and QR Codes." Proceedings of 2014 IEEE International Symposium on Innovation in Intelligent Systems and Applications, INISTA, Italy.

European Committee for Standardization. 2003. "EN 13186-Transportation; Logistics and Services; Public Passenger Transport; Service Quality Definition, Targeting, and Measurement."

European Parliament. 2014. "Integrated Urban E-Ticketing for Public Transport and Touristic Sites." Science and Technology Options Assessment, European Parliamentary Research Service, PE 513.551.

European Union. 1998. "QUATTRO-4th F.P. Project, Quality Approach in Tendering/ Contracting Urban Public Transport Operations. Final Report, Synthesis and Recommendations. http://www.transport-research.info/web/projects/project_ details.cfm?id=636.

Finzgar, L., and M. Trebar. 2011. "Use of NFC and QR Code Identification in an Electronic Ticket System for Public Transport." Proceedings of the 19th International Conference on Software, Telecommunications and Computer Networks (SOFTCOM), Croatia.

Ganesan, K., J. A. Rahman, and S. Jain. 2012. "Bus Route Information Retrieval through Visual Codes Using Camera Enabled Cellphones." International Journal of Traffic and Transportation Engineering, 1(2): 7-12.

Greenlaw, C., and S. Brown-Welty. 2009. "A Comparison of Web-Based and PaperBased Survey Methods: Testing Assumptions of Survey Mode and Response Cost." Evaluation Review, 33: 464-480.

Grönroos, C. 1988. "Service Quality: The Six Criteria of Good Service Quality." In Review of Business. New York: St. John's University Press. 
Hu, K. C. 2010. "Evaluating City Bus Service Based on Zone of Tolerance of Expectation and Normalized Importance." Transport Reviews, 30(2): 195-217.

Lai, W., and C. Chen. 2011. "Behavioral Intentions of Public Transit Passengers - The Roles of Service Quality, Perceived Value, Satisfaction and Involvement." Transport Policy,18(2): 318-325.

Lehtinen, U., and J. Lehtinen. 1982. Service Quality—A Study of Quality Dimensions. Service Management Institute, Helsingfors.

Lin, W., and G. G. Van Ryzin. 2012. "Web and Mail Surveys: An Experimental Comparison of Methods for Nonprofit Research." Nonprofit and Voluntary Sector Quarterly, 41: 1014-1028.

Mendelson, J., and J. Romano. 2013. "Age Differences in the Knowledge and Usage of QR Codes. Universal Access in Human-Computer Interaction. User and Context Diversity. Lecture Notes in Computer Science, 8010: 156-161.

Okazaki, S., A. Navarro, and S. Campo. 2013. "Cross-Media Integration of QR Code: A Preliminary Exploration." Journal of Electronic Commerce Research, 14(2).

Parasuraman, A., V. A. Zeithaml, and L. L. Berry. 1985. "A Conceptual Model of Service Quality and Its Implications for Future Research." Journal of Marketing, 49: 41-50.

Sankara Narayanan, A. 2012. "QR Codes and Security Solutions." International Journal of Computer Science and Telecommunications, 3(7), July: 69-72.

Spitz, G. M., F. L. Niles, and T. J. Adler. 2006. "Web-Based Survey Techniques: A Synthesis of Transit Practice." TCRP Synthesis 69, Transportation Research Board, Washington, DC.

Transportation Research Board. 1999. "A Handbook for Measuring Customer Satisfaction and Service Quality." TCRP Report 47.

Transportation Research Board. 2005. Transit Capacity and Quality of Service Manual, Second Edition.

Weinstein, A. 2000. "Customer Satisfaction among Transit Riders. How Customers Rank the Relative Importance of Various Service Attributes." Transportation Research Record, 1735: 123-132.

Zhang, M., D. Yao, and Q. Zhou. 2012. "The Application and Design of QR Code in Scenic Spot's e-Ticketing System-A Case Study of Shenzhen Happy Valley." International Journal of Science and Technology, 2(12), December: 817-822. 


\section{About the Authors}

BEGoñA GUIRAO (bguirao@caminos.upm.es) is a full-time lecturer at the Universidad Politécnica in Madrid (UPM), Transportation Department. Her research interests include transport policy, planning, and economics. Her initial research publications centered on the impact of the new high-speed HSR lines on modal choice and induced demand; in recent years, she has shifted the focus of her research to public transport use in cities, particularly the analysis of the impact of service quality perception on user behavior.

Antonio García (Antonio.garcía@crtm.es) is a civil engineer and Head of Studies of the Planning Department at the Consorcio Regional de Transportes de Madrid (Madrid Regional Transport Consortium-CRTM). He has extensive experience as a consultant in urban public transport and is currently writing his doctoral thesis at UPM on the subject of service quality perception in public transportation and its impact on operators' income statements.

MARíA EUGENIA LóPEZ (melopezlambas@caminos.upm.es) is a full-time lecturer at UPM (Transportation Department), where she teaches Transport Economics. She specializes in sustainable urban mobility plans and public transport.

CARLOS ACHA (Cdacha@alsa.es) is a civil engineer and Operations Director at ALSA (ALSA Grupo), the leading operator in the Spanish sector of passenger transport by road, at which he has more than 15 years of extensive experience. With more than 100 years of experience and a vocation of continuous innovation, ALSA is integrated into the National Express Group, an international public transport operator running buses, coaches, and railways in the UK, Continental Europe, North America, North Africa, and the Middle East.

JULIO COMENDADOR (jcomendador@caminos.upm.es) is a civil engineer and Ph.D. candidate at UPM. His doctoral thesis involves the development of a methodology for studying willingness to change patterns of urban mobility with the introduction of transport policy measures. 